\title{
“PELO BEM OU PELO MAL, ATÉ QUE EU AJUdEI BASTANTE GENTE, NÉ?"
}

\section{"FOR GOOD OR FOR EVIL, I THINK I'VE HELPED A LOT OF PEOPLE, RIGHT?"}

\section{Entrevista com o professor Marcelo Tonil}

RT: Prezado professor Marcelo Toni, sabemos que o falecimento recente do maestro e professor Olivier Toni, seu pai, deixa uma lacuna no campo musical no que se refere à trajetória dele, que reuniu atividades de composição, direção musical, ensino, pesquisa e extensão, além de sua militância política e suas posições de esquerda. Sua última composição, Navio Negreiro, estreada no último Festival Música Nova², reafirma esse legado transdisciplinar. No seu caso, como filho de Toni, como the parece esse legado?

Marcelo Toni: Interessante você ter perguntado como filho "de" Toni. Mesmo que tenha sido falha de digitação não é como ser irmão "da" Claudia ou "da" Flávia. Como se fosse um estigma ser Toni. Mas sabemos que não é bem assim. Eu e minhas irmãs, assim como você e tantos outros alunos, acabamos recebendo um pouco desse legado "do" Toni. Mas ser "de" família Toni também é um legado que nos remete aos antepassados do meu pai que vieram de uma Europa colonialista, devastada pela guerra e devastada também por uma onda racista e conservadora do final do séc. XIX, que ora se volta em pleno séc. XXI. Como dizia o velho Toni: é de arrepiar. Talvez tenha sido essa a grande lição que meus avós passaram para o meu pai, que é sobre a intolerância de qualquer natureza e o total desapego às coisas materiais. E o próximo passo nessa trajetória seria a vinculação de meu pai com as ideias de esquerda, a Faculdade de Filosofia e até sua filiação ao PCB.

I Entrevista realizada por e-mail, pelo editor-gerente da Revista da Tulha, Prof. Dr. Marcos Câmara de Castro.

2 Obra apresentada no 50 Festival Música Nova Cilberto Mendes, realizado em Ribeirão Preto, de 8 a 12 de novembro de 2016. Navio Negreiro foi interpretada pela soprano Isabella Luchi, acompanhada pela orquestra USP-Filarmônica, sob a direção de Rubens Ricciardi, no dia 10 de novembro, na Sala de Concertos da Tulha, campus da USP em Ribeirão Preto. 
A composição Navio Negreiro, além de ser um manifesto contra tudo aquilo que existe de mais estúpido na raça humana, tem o propósito de mostrar a grande contradição que existe entre o bem e o mal. Não foi à toa que meu pai terminou o Navio com a citação do coral Komm süsser Tod - venha, ó doce morte. A morte anunciada por um coral branco e luterano (mais europeu, impossivel) do homem branco que se ajoelha diante do santo padre e depois joga negros ao mar para serem devorados pelos tubarões, as doze notas do sistema tonal cristão europeu contra as 6 notas do canto dos negros africanos pagãos. E essa passagem do poema de Castro Alves deixou meu pai muito atormentado nos seus últimos meses de vida. Como se ele, ateu convicto por anos, passasse a acreditar que um dia seria ele engolido pela barriga do enorme peixe.

RT: A intensidade dramática de sua última composição, em que o Sr. vê inclusive o apelo místico, insere-se no contexto de sua obra musical, parte dela recentemente gravada pelo selo SESC. O Sr. participou desse trabalho de alguma maneira, ou acompanhou mais de perto essa produção? Em caso afirmativo, como foi, ainda que no plano afetivo?

Marcelo Toni: Esse apelo não é tão recorrente assim. $\bigcirc$ mesmo misticismo ele vê nos poemas do Mao, Poe, Castro Alves... Ele precisa ter uma dedicatória antes de escrever. Algo ou alguém que o justifique. amigo violinista, o amigo pianista, a esposa, filhos, netos... Enquanto ele escrevia o Navio pedia opiniões ao seu médico oncologista. Aliás foi esse mesmo médico que sugeriu que o Navio fosse como um oratório, ou usar uma musa de inspiração, como as musas dos poetas do período do Castro Alves. Meu pai não escrevia com o profissionalismo dos compositores que só fazem isso. Nunca teve um projeto a realizar, de ficar pesquisando, pesquisando... Nunca se sentiu obrigado a escrever, apenas escrevia embalado pelo entusiasmo de uma nova ideia. Ou por alguém por quem ele nutria uma grande admiração. Era um romântico! Era capaz até de conversar com o zelador do prédio sobre o que estava fazendo e filosofava com seus próprios botões. Se a ideia brotava enquanto sonhava, anotava no caderninho ao lado da cama. E passava o dia seguinte inteiro com o caderninho no bolso da camisa. Mostrava para mim, para o seu neto Eduardo, para o médico... 
Foram minhas irmãs que participaram mais intensamente da produção do CD. Elas mais o Claudio Cruz. Eu apenas participei de uma única música, as "Três Variações". E pela própria educação que recebi dele, e ainda corroborado com a postura ética de minha família, nunca houve parentesco no trabalho. Jamais poderia dizer que tocar com ele ou tocar suas músicas tenha sido diferente do que tocar músicas de seus alunos e professores. Sinto um imenso orgulho, sim, de olhar à minha volta e compartilhar com pessoas que passaram por todas as instituições que ele criou. Na verdade, esse sentimento seria mais justo se partisse daquelas pessoas que às vezes se esquecem o que e como foi possivel elas estarem ali trabalhando, estudando e sustentando suas vidas graças ao meu pai. Então não posso desfrutar sozinho desse sentimento, que deveria ser um sentimento de todos.

RT: $\bigcirc$ Sr. citou "as instituições que ele criou”, que podem ser consideradas entre as grandes obras de seu pai. Como o Sr. vê hoje a situação e o estado das instituições que ele criou? Em especial, o Sr. poderia falar um pouco sobre os destinos da Orquestra Sinfônica Jovem Municipal, criada no ensejo da fundação da Escola Municipal de Música, hoje uma das principais referências do estudo musical público e gratuito na cidade de São Paulo?

Marcelo Toni: $\bigcirc$ [prefeito] Faria Lima queria uma orquestra igual à Orquestra Jovem da Bulgária, só que na Bulgária existem escolas e aqui não. Ah, então façamos uma escola! Como dizia meu pai, a galinha veio depois do ovo. E hoje a OSJM, que mudou de nome por decreto da prefeita Erundina (como se um dia você, que se chama Marcos, no dia seguinte acordasse Silvia, por decreto), está desvinculada da Escola. Mas desvinculada elas sempre foram porque não passa pela cabeça de maestros que, se tem escola, tem que ter orquestra em função do ensino e aperfeiçoamento e não para satisfazer o ego deles. Houve uma tentativa do maestro Neschling de colocá-la no seu devido lugar, mas a atual administração está cuidando de separá-las novamente.

Mas temos uma escola que, comparativamente com outras instituições país afora, até que tem dado algum resultado porque os professores, cada um à sua maneira, dedicam-se e gostam de estar lá, e muitos de seus alunos concluem seus estudos no exterior. Mas acho também que a Escola devia estar nas mãos de quem entende de educação. $\bigcirc$ lugar dela devia ser na secretaria da educação com quem entende de gestão escolar e não na 
cultura. Como pode um curso de piano durar 24 semestres? $\bigcirc$ aluno entra na escola com 10 e sai casado e com filhos e um diploma de piano!!! É triste, ninguém consegue concluir um curso. Até o curso de flauta doce dura quase uma década. Também, ao criar a Osusp [Orquestra Sinfônica da USP], a ideia era ter uma orquestra de nivel profissional, que servisse aos estudantes de música. Mas mais uma vez aquelas senhoras gorduchinhas, de óculos na ponta do nariz, frustraram os planos do Toni. É como ter um hospital universitário sem que professores e alunos trabalhem nele.

Costaria de acrescentar minha visão disso tudo. Veja, minha filha Paula, que estudou na EMMSP, quando dizia que morava na Vila Mariana, se sentia envergonhada, porque o colega mais perto de nossa residência vinha de Ferraz de Vasconcelos. Não dá para aceitar calado que uma Escola que devia servir a todos os cidadãos da capital não esteja presente nas escolas de ensino básico e fundamental, oferecendo cursos profissionalizantes de música. A Escola de música vai fazer 50 anos em 2019 e continua prometendo aos seus alunos que sairão grandes solistas que só tocam o repertório do sec. XIX. Ainda continua vivendo um modelo europeu falido que nem os meninos cantores de Viena acreditam mais. É necessário um grande projeto pedagógico e interdisciplinar, envolvendo pais e professores, e não só alguns privilegiados. A música, de todas as manifestações artísticas, é a que mais se reinventa. Meu pai, aos 90, queria mudanças e os de 40, 50 ainda vivem num passado colonialista e de prepotência. É assim que acham que se faz música. Pobres de nós que herdamos essa luta sem fim.

RT: Que caminhos o Sr. acha que os músicos atuais deveriam seguir, se desejassem se inspirar nas propostas do Prof. Toni quanto à educação musical? Quais as ações mais urgentes e quais a longo prazo, no seu entender?

Marcelo Toni: Os músicos precisam saber porque a música é necessária. Essa era uma tese que surgiu nos anos de filosofia que meu pai fez na USP, mas não concluiu. Seu grande amigo e mestre, o professor Cruz Costa, achava que meu pai devia se dedicar em tempo integral à música e não perder tempo com a filosofia, que ele refletisse muito sobre a necessidade da música. Tirar o foco da performance e direcionar para práticas coletivas que não sejam apenas os modelos tradicionais. Não basta 
apenas criar cursos técnicos de música, é preciso encarar o ensino com interesse científico. As novas tecnologias e meios de expressão, os laboratórios de criação eletroacústica, as pesquisas voltadas à etnomusicologia.

Acho que um ótimo exemplo de possibilidades é o Festival de Música de Câmara do SESC, que mostra que existe vida musical muito inteligente longe das orquestras. Não só pela prática em conjuntos de diversas formações, mas por fazer conhecer música de qualidade de compositores desconhecidos. Mas o músico precisa ousar e não se acomodar.

RT: $\bigcirc$ Sr. citou a Osusp. $\bigcirc$ que mais o Sr. sabe sobre a criação da Osusp, também criada pelo Toni, sobre a qual ele nunca disse muita coisa, e a mudança de rumos que ela tomou, quando logo saiu de sua esfera de influência?

Marcelo Toni: Nesse vídeo ótimo, ele fala tudo sobre a Osusp e aproveite e pegue o seu lenço para matar as saudades do vovô: $<$ https://goo.gl/7Cc3ul>.

Mas esse vídeo tem cortes. No site da ECA acho que está completo. Meu pai sempre teve uma amargura muito grande com relação a Osusp. E falar nesse assunto publicamente era campo minado por envolver - Guarnieri, que nunca teve culpa de nada, mas estava lá. Até o fim da vida, mesmo aposentado e longe da ECA, entra reitor, sai reitor, ele sempre tentava convencê-los que não havia sentido gastar com uma orquestra dentro da USP que não serve para nada sem estar vinculada ao Departamento de Música. $O$ que ele menos se conformava era a quantidade de músicos extras, pagos com cachê, numa orquestra que foi criada para ser uma orquestra de câmara. A USP sem dinheiro gastando com uma orquestra para fazer Mahler. E fizeram a Sagração [da Primavera, de Stravinsky] em 2013. Devia ter pelo menos uns 40 fazendo extra lá. Ainda que fosse pra tocar músicas dos alunos que se formam na USP... Nem que fosse um prêmio de consolação para eles. Mas o que se esperar de um país que constrói ferrovias que dão a lugar nenhum, um presidente que diz para o outro "between" achando que está dizendo "entre"!

RT: Essa sua resposta esclarece as razões das reticências do Prof. Toni com relação à Osusp, já que se tratava da integridade moral de Camargo Guarnieri. Aliás, o que o Sr. sabe sobre a relação entre os dois, Toni e Guarnieri? 
Marcelo Toni: Sempre dentro da cordialidade. Não lembro do Guarnieri frequentando nossa casa. Não era como o Willy [Corrêa de Oliveira] e seus alunos ou o próprio Toni que muitas vezes saía de madrugada para levar alunos para casa. Mas o fato do Guarnieri ter ido para a Osusp colocou uma pedra de gelo na relação entre eles, que começou a derreter 10 anos depois, com um convite feito pelo próprio Toni para o Guarnieri conhecer $\circ$ Departamento de Música da ECA, quando ainda era no Bloco B9. Alunos tocaram músicas do Guarnieri, houve um almoço onde os dois se abraçaram e houve muita comoção. Mas a questão da Osusp continuava a mesma e o mais incrivel é que meu pai criou mais duas orquestras dentro da USP. Primeiro foi aquela com os melhores músicos de São Paulo - todos solistas renomados. Numa canetada só, contratou doze músicos que ensaiariam, fariam concertos e dariam aulas no Departamento. Fato inédito na USP. Ninguém conseguia entender como meu pai conseguiu contratar doze professores de uma vez só. Mas esses músicos, com os vícios de sua profissão, não discerniam o público do privado e a coisa descambou. Quando meu pai descobriu que estavam usando a USP para seus interesses particulares, mais uma vez de uma canetada só, demitiu todos eles. Ele era assim, obstinado com seus ideais; dava murro na mesa se fosse preciso. E depois veio a Ocam [Orquestra de Câmara da USP], dentro do Departamento, dessa vez tocando obras e sendo regida por alunos da extensão e da própria USP. Foi o que deu para fazer, e a USP agora tem duas orquestras graças ao meu pai. Como ele mesmo dizia, "pelo bem ou pelo mal até que eu ajudei bastante gente, né?".

\section{Sobre o entrevistado}

Marcelo Toni é fagotista da Orquestra Sinfônica Municipal de São Paulo.

Recebido em: 30/01/2018

Aprovado em: 30/0 I/2018 